\title{
Expansão urbana e hidrografia: modelagem urbana com autômatos celulares para Dom Pedrito/RS 1
}

\section{Urban sprawl and hydrography: urban modeling with cellular automata to Dom Pedrito/RS}

\author{
Baumbach, Flavio'; Polidori, Mauricio² \\ 1 Universidade Federal de Pelotas, Rua Benjamin Constant, 1359, Brasil, \\ flavio.baumbach@gmail.com \\ 2 Universidade Federal de Pelotas, mauricio.polidori@gmail.com
}

\begin{abstract}
RESUMO
O crescimento urbano em áreas de interesse ambiental ov em áreas de risco para a vida tem acumulado problemas e exigido novas alternativas para o futuro das cidades, indicando a necessidade de novas estratégias que associem planejamento urbano e ambiental, na busca de integração entre cidade e natureza. Nesse caminho, a modelagem urbana com autômatos celulares é uma ferramenta para a simulação de diferentes possibilidades de expansão territorial, de modo a antecipar cenários de futuro e a permitir uma comparação analítica. Este trabalho apresenta considerações sobre a relação entre cidade e ambiente hídrico, e um estudo de caso com recursos de modelagem urbana em ambiente celular, sobre crescimento urbano e áreas alagáveis para a cidade de Dom Pedrito/RS. Os resultados indicam diferentes possibilidades de crescimento urbano sobre as áreas de cheias naturais.
\end{abstract}

Palavras-chave: Crescimento urbano, Expansão urbana, Autômato celular.

\begin{abstract}
The urban sprawl in areas of environmental interest or in risk areas accumulates problems and required new alternatives for the future of cities, indicating the need for new strategies that associate urban and environmental planning to attempt integration between city and nature. Urban modeling with cellular automata is a tool for simulating different possibilities of urban sprawl, in order to anticipate future scenarios and allow an analytical comparison. This paper explores the connection between the city and the water environment, as well a case study with urban modeling in cellular automata, on urban growth and wetlands for the city of Dom Pedrito/RS. The results indicate different possibilities of urban sprawl on natural flood areas.
\end{abstract}

Keywords: Urban growth, Urban sprawl, Cellular automata.

\footnotetext{
${ }^{1}$ BAUMBACH, Flavio; POLIDORI, Mauricio. Expansão Urbana e Hidrografia: Modelagem Urbana com Autômatos Celulares para Dom Pedrito/RS. In: II SIMPÓSIO NACIONAL DE GESTÃO E ENGENHARIA URBANA: SINGEURB, 2019, São Paulo. Anais... Porto Alegre: ANTAC, 2019.
} 


\section{INTRODUÇÃO}

Desde a Antiguidade o homem utilizou o ambiente hidrográfico como recurso hídrico. Pela possibilidade de pesca, irrigação e locomoção, foi perto de rios que as pessoas se aglomeraram e as cidades nasceram (PORATH, 2004). O acesso à água possibilitou o desenvolvimento da agricultura em larga escala e a transformação dos pequenos aglomerados urbanos em cidades, eram as civilizações hidráulicas (ABIKO, 1995; SOJA, 2000).

Foi ainda na Antiguidade que o homem associou a água suja e o acúmulo de lixo à proliferação de doenças. Os gestores urbanos, então, aprenderam a relação entre abastecimento de água e afastamento das águas servidas. Fornecer água limpa e escoar a água utilizada foi uma necessidade que ocorreu através de técnicas de controle como a construção de diques e canalizações superficiais ou subterrâneas. Nas antigas cidades da Mesopotâmia foram encontrados vestígio de redes de água e esgoto, marcando o início do saneamento básico (SOUZA, 2009).

Muito tempo depois, já na segunda Revolução Industrial, com o aumento das cidades e da população urbana, as condições de saneamento voltaram a ter importância na infraestrutura urbana. As reformas urbanas higienistas, como as de Paris por Haussmann, a partir de grandes intervenções sobre a hidrografia natural, exemplificam o paradigma que prevaleceu sobre 0 manejo das águas urbanas até metade do século XX (MUMFORD, 1961; PERES, 2010). Estas intervenções estruturalistas e não integradoras, de caráter higienista, consistiam em prover água de fontes seguras e coletar os efluentes para despejá-los à jusante dos cursos d'água, sem tratamento (TUCCl, 2008). Neste aspecto, conforme Gorski (2010), os rios, córregos e demais linhas de drenagem, nas cidades, tiveram suas margens concretadas e foram enclausurados em galerias que recebem todo o tipo de efluente. Assim, ainda conforme Gorski (2010), a urbanização anulou a importância dos rios, restringindo sua presença a sintomas perturbadores como mau cheiro, obstáculo à circulação e ameaça de inundação.

Conforme Peloggia (1997), é nas concentrações urbanas que a ação do homem se amplia e diversifica. E sobre os sistemas morfodinâmicos fluviais, conforme Nir (1983) e Drew (1989) que ocorrem as maiores alterações físicas e ambientais do meio natural para o desenvolvimento das atividades humanas. É nas cidades então, que temos os maiores impactos ambientais sobre a paisagem hídrica. Desonie (2008) e Peres (2010), afirmam que a hidrografia é o atributo da paisagem natural que mais se destaca no processo de urbanização.

Para o meio ambiente isto não é positivo. Conforme Finkler (2012), o desenvolvimento urbano provoca impactos sobre o sistema hídrico quantitativamente, com variação da qualidade da água, e qualitativamente, com alteração dos padrões de fluxo e quantidade da água. Para Finotti (2009), conforme a mancha urbana cresce, em mesma significância cresce a degradação ambiental relacionada à geração de esgoto, efluentes, e resíduos sólidos domésticos e industriais.

Além disso, a expansão das áreas urbanas nem sempre ocorre com planejamento. Conforme relatório World Cities Report (2016), do Programa para Assentamentos Humanos das Nações Unidas (United Nations Human Settlements Programme - UN-HABITAT), as favelas ou assentamentos informais na Ásia, na África e na América Latina continuam a crescer. Conforme o relatório Atlas of the Human Planet (2016) do Centro Comum de Investigação da Comissão Européia (Joint Research Centre - JRC), mais da metade da população mundial vive em cidades. Assim, planejar uma expansão urbana que considere aspectos do ambiente natural é um desafio contemporâneo.

A partir dos anos 90 se fortaleceu o paradigma do desenvolvimento sustentável, que considera a ação de medidas não estruturais sobre os sistemas naturais. Assim, conforme Tucci (2008), a principal diretriz de planejamento de medida não estrutural é uma urbanização que preserve os caminhos naturais de drenagem e escoamento, priorizando a infiltração das águas no solo, em detrimento às medidas estruturais, que envolvem grandes ou pequenas obras de planeamento que alteram a paisagem natural e as características ambientais.

Frente a isto, o planejamento urbano e ambiental trabalha na elaboração e implementação de projetos que considerem maior sustentabilidade e mitigação da degradação ambiental 
dos sistemas naturais. As preocupações do homem com o meio ambiente, associando questões sociais, ecológicas e econômicas com uso racional dos recursos hídricos se fortalece na ideia de preservação dos recursos naturais para melhorar a qualidade de vida da população (SANTOS, 2004).

Paralelamente, a Teoria Geral dos Sistemas influenciou os estudos urbanos contemporâneos assim como várias outras áreas do conhecimento. Considerando o dinamismo das cidades, onde diferentes fatores e agentes interagem e contribuem para um constante processo de evolução, a expansão das áreas urbanas requer novos processos metodológicos que possam prever ações ou colaborar com soluções de planejamento urbano e ambiental. Polidori (2004) indica que o estudo da cidade e do crescimento urbano tenha suporte na teoria geral dos sistemas, nos estudos de modelagem e nas teorias da complexidade.

Neste sentido, simulações de expansão e crescimento urbano com recursos de modelagem urbana baseado na Teoria dos Autômatos Celulares são utilizadas como instrumentos de apoio à gestão e ao planejamento das cidades, como aponta Liu (2009), que afirma que os estudos urbanos em ambiente celular permitem um modelo urbano que funcione como uma ferramenta analítica para avaliar o impacto de leis ou de fatores que influenciam no processo de desenvolvimento urbano.

Com base no exposto, será apresentado um trabalho de modelagem urbana em ambiente celular para a cidade de Dom Pedrito/RS, onde de maneira analítica se observou a relação de crescimento urbano sobre as áreas de inundação naturais.

\section{METODOLOGIA}

Para realizar as simulações foi utilizada a plataforma CityCell (disponível em https://wp.ufpel.edu.br/citycell/), desenvolvida no Laboratório de Urbanismo da Faculdade de Arquitetura e Urbanismo da Universidade Federal de Pelotas - LabUrb/Faurb/UFPel.

A plataforma CityCell, é uma ferramenta de análise espacial baseada na Teoria dos Autômatos Celulares. Assim, opera através de uma matriz de células retangulares, onde o estado de cada célula é determinado a partir do estado das células vizinhas e por um conjunto pré-determinado de parâmetros e regras de transição entre tempos.

O processo de simulação de expansão da área urbanizada através da plataforma CityCell foi baseado nas etapas de: a) inputs, ou entrada de dados, que é a representação dos atributos do território no ambiente celular; b) processamento, a partir dos parâmetros e das regras de transição; c) obtenção dos resultados, ou outputs; e d) análise dos resultados.

Para a criação dos inputs, a área de estudo (cidade de Dom Pedrito/RS) foi seccionada em células quadradas que representam $200 \mathrm{~m}$ cada. Assim, obteve-se uma malha de $46 \times 46$ células, que representa uma área de $8500 \mathrm{ha}$. Cada célula recebeu um atributo, natural ou urbano, podendo cada atributo pode gerar uma tensão de resistência ou de atração à urbanização. Os inputs, ou atributos a seguir descritos foram gerados a partir da interpretação dos dados morfológicos de uso do solo em imagens Landsat8, bandas 3,2,1, de 2016.

A Figura 1 demonstra os inputs separadamente: a) imagem do satélite Landsat8, do ano de 2016, usada como base para a construção dos atributos; b) representa a sobreposição dos atributos; c) atributo aleatório, random em cinco classes, natural e resistência, usado para atribuir um grau de aleatoriedade às simulações; d) área efetivamente urbanizada em 2016 , urbano e atração; e) rodovia federal, urbano e atração; f) estradas vicinais, urbano e atração; g) açudes e barragens, urbano e resistência; h) área alagável, natural e resistência; i) arroios e córregos, natural e resistência; j) rio Santa Maria, natural e resistência; k) mata plantada ou nativa, natural e resistência; e l) campos e plantações, natural e resistência.

Na geração de cenários os inputs podem ser ativados ou desativados, dependendo da relação que se busca no processo. Também podem ter seu parâmetro de atração ou resistência alterado, podendo assumir pesos distintos em diferentes processos. Assim, uma área de vegetação nativa, por exemplo, pode representar atração à urbanização em um processo, e resistência à urbanização em outro. 
Figura 1 - Parâmetros e atributos modelados na plataforma CityCell
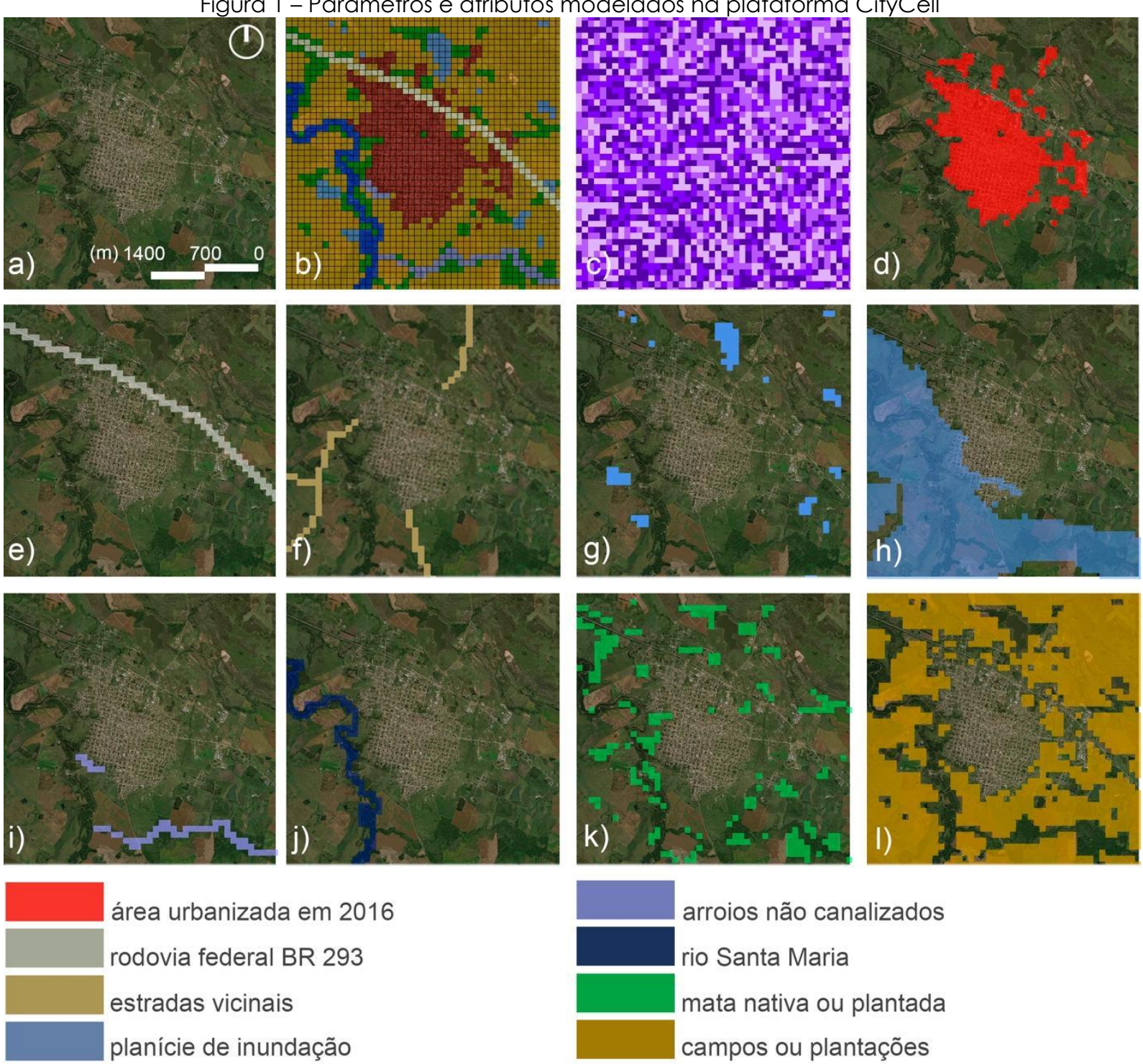

Fonte: Os autores (2019)

Dos processos realizados neste estudo, selecionamos dois para representar a relação de expansão urbana sobre o ambiente hídrico. Para as duas simulações a regra de crescimento urbano utilizado foi a "Threshold Potencial", que segundo Polidori (2004) considera a lógica de centralidade-potencial celular para orientar o crescimento das células urbanas. Os cenários foram processados com 50 iterações, o que representa 50 tempos de transição.

\section{RESULTADOS}

No cenário 1 era possível a ocupação das áreas alagáveis (atributo h) e dos arroios e córregos (atributo i). O atributo açudes e barragens (atributo g) foi congelado, significando que neste processo o estado de suas células não pôde ser modificado. A área efetivamente urbanizada, rodovia federal e estradas vicinais (atributos $d$, e e f) foram considerados atração à urbanização. Mata nativa ou plantada e campos ou plantações (atributos $k e l$ ) representaram resistência à urbanização, mas suas células puderam assumir novos estados.

Já no cenário 2 as áreas alagáveis, os arroios e córregos e os açudes e barragens (atributos $\mathrm{g}, \mathrm{h}$ e i) foram congelados, sem possibilidade de alteração do estado destas células. Área efetivamente urbanizada, rodovia federal e estradas vicinais (atributos $d$, e e f) continuaram considerados atração à urbanização, assim como mata plantada ou nativa e campos ou plantações (atributos $k$ el) continuaram atributos naturais de resistência à urbanização. 
Como esperado os dois cenários apresentaram diferentes tendências de crescimento urbano. Comparando a iteração de tempo 50 para os dois cenários (Figura 2), podemos perceber que o cenário 1 urbanizou células em áreas de alagamento, já o cenário 2 não permitiu a urbanização destas áreas. O cenário 2, portanto, apresenta-se como mais adequado à expansão urbana devido a minimização dos conflitos hídricos.

Figura 2 - Iteração de tempo 50 para os cenários 1 e 2, com sobreposição das áreas alagáveis

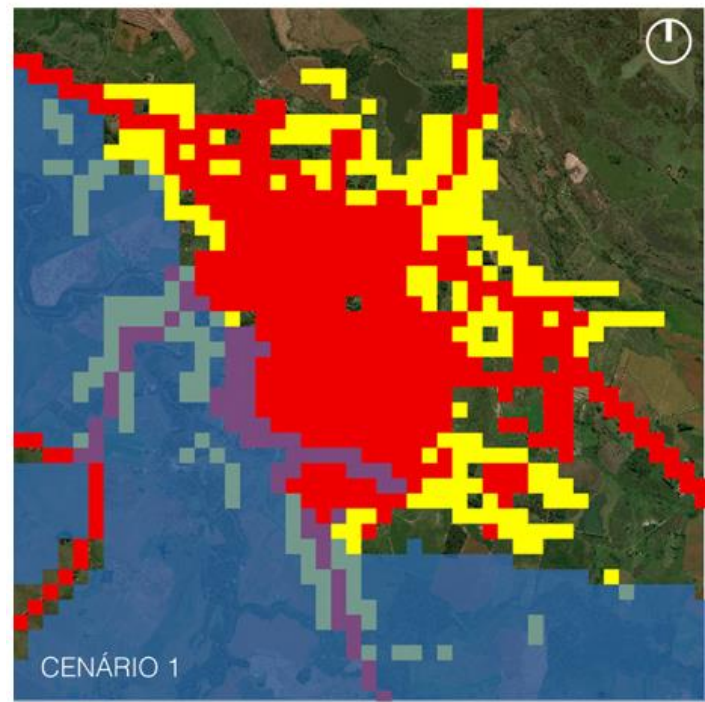

áreas não alagáveis

áreas alagáveis

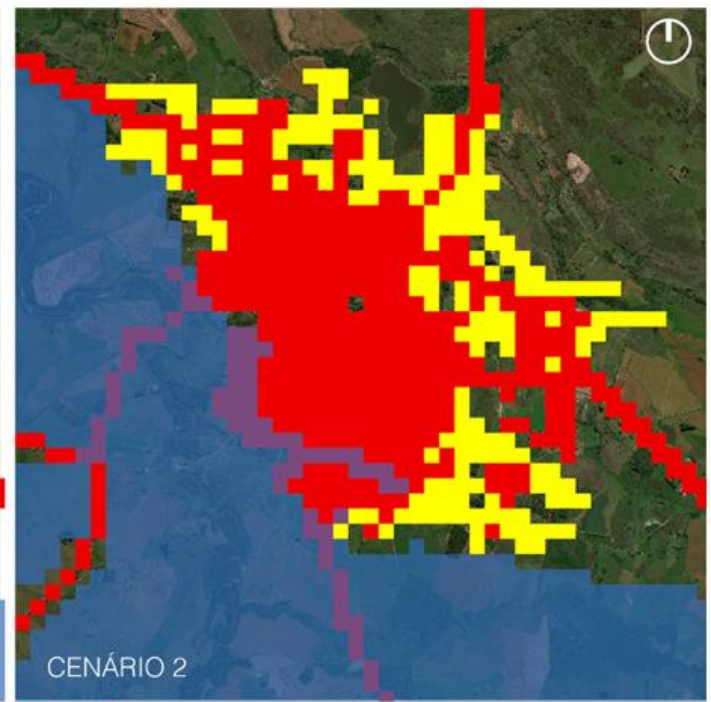

área efetivamente urbanizada 2016

projeção de crescimento urbano

Fonte: Os autores (2019)

Devido ao nível de desagregação espacial, córregos e canais retificados foram considerados como atributo urbano. Para simplificação, matas nativas, matas plantadas, campos e plantações foram considerados como resistência à urbanização com mesmo peso, o que pode não representar com exatidão o contexto e as dinâmicas locais.

\section{CONCLUSÕES}

O desenvolvimento das atividades humanas altera o relevo natural modificando as dinâmicas da natureza. Dentre as atividades humanas, o processo de urbanização se destaca pela capacidade de alteração e degradação dos sistemas ambientais, sobretudo o ambiente hídrico.

A preocupação com um desenvolvimento sustentável (ou mitigatório) estimula a criação de metodologias que integre planejamento urbano e ambiental como estratégias na busca da conexão entre território, natureza e sociedade, a fim de promover a melhoria da qualidade de vida nas cidades.

Assim, simulações de crescimento urbano com recursos de modelagem urbana baseada em autômatos celulares podem servir, como demonstrado no estudo, como um instrumento capaz de fornecer subsídios à tomada de decisão em projetos que busquem a integração entre planejamento urbano e ambiental.

\section{REFERÊNCIAS}

ABIKO, Alex Kenya; et al. Urbanismo: história e desenvolvimento. São Paulo: EPUSP, 1995.

DESONIE, Dana. Our Fragile Planet; Geosphere: The Land and Its Uses. Chelsea House. New York, 2008. 
DREW, David. Processos interativos homem-meio ambiente. 2.ed. Rio de Janeiro: Bertrand Brasil, 1989.

FINKLER, R. Planejamento, manejo e gestão de bacias hidrográficas. Unidade 1, apostila didática. Projeto água e gestão. Itaipu Binacional, ANA, 2012.

FINOTTI, A.R.; FINKLER, R.; SILVA, M.D.; CEMIN, G. Monitoramento de recursos hídricos em áreas urbanas. Caxias do Sul: EDUCS, 2009.

GORSKI, Maria C. B. Rios e cidades: ruptura e reconciliação. São Paulo: Senac, 2010.

LIU, Yan. Modelling Urban Development with Geographical Information Systems and Cellular Automata. Taylor \& Francis Group, 2009.

MUMFORD, Lewis (1961). A Cidade na História. São Paulo: Martins Fontes, 2004.

NIR, Dov. Man, a geomorphological agent. Jerusalem: Keter Publishing House, 1983.

PASARESI, Martino; et al. Atlas of the Human Planet 2016: Mapping Human Presence on Earth with the Global Human Settlement Layer. Luxemburgo: 2016.

POLIDORI, Maurício C. Crescimento urbano e ambiente: um estudo exploratório sobre as transformações e o futuro da cidade. Tese Doutorado UFRGS PPGECO, 2004.

PELOGGIA, Alex Ubiratan. A ação do homem enquanto ponto fundamental da geologia do Tecnógeno. Revista Brasileira de Geociências, v.27, n.3, 257-268, 1997.

PERES, Otavio M. Crescimento Urbano e Hidrografia: dinâmicas morfológicas e articulação à paisagem natural. Dissertação (Mestrado em Arquitetura e Urbanismo) - Faculdade de Arquitetura e Urbanismo, Universidade Federal de Pelotas, Pelotas, 2010.

PORATH, Soraia Loechelt. A paisagem de rios urbanos: a presença do Rio Itajaí-Açu na cidade de Blumenau. Dissertação (Mestrado em Arquitetura e Urbanismo) - Programa de Pós-graduação em Arquitetura e Urbanismo, UFSC, Florianópolis, 2004.

SANTOS, Rosely Ferreira. Planejamento Ambiental: Teoria e Prática. São Paulo, 2004.

SARAIVA, Marcus Vinicius Pereira; POLIDORI, Maurício Couto. CityCell: Urban Growth Simulator (software). LabUrb - Laboratório de Urbanismo da FAUrb. Pelotas: UFPel, 2014.

SOJA, Edward W. Postmetropolis. Estudios criticos sobre las ciudades e las regiones. Madri, Traficantes de Suenos, 2000.

SOUZA, F. S. Saneamento básico na história da humanidade. In: COMISSÃO DE SERVIÇOS DE INFRAESTRUTURA DO SENADO FEDERAL. Brasília, 2009.

TUCCl, Carlos E. M. Águas Urbanas. Revista Estudos Avançados 22 (63); 97-1 12, 2008.

United Nations Human Settlements Programme (UN-HABITAT). World Cities Report. Nairobi, 2016. 